\title{
Pendidikan Kesehatan Gizi Usia Sekolah sebagai Upaya Peningkatan Prestasi Belajar SDN Purworejo 03 Geger Madiun
}

\author{
Lucia Ani Kristanti ${ }^{1}$, Cintika Yorinda Sebtalesy ${ }^{2}$ \\ STIKES Bhakti Husada Mulia, Jl. Taman Praja No.25, Mojorejo, Kec. Taman, Kota Madiun, Jawa \\ Timur 631391,2 \\ Email: cintikayorindas@gmail.com ${ }^{1}$
}

\begin{abstract}
ABSTRAK
Usia 6-12 tahun merupakan usia anak pada masa sekolah. Standar pertumbuhan fisik dan standar kemampuan yang normal dan wajar akan dimiliki oleh anak usia pada masa sekolah yang sehat sesuai kriteria sehat pada usianya. Proses belajar di masa depan pada anak usia sekolah dasar akan dipengaruhi oleh pertumbuhan dan perkembangannya di masa awal belajar ini. Maka daripada itu, penunjang kondisi otak agar berprestasi yang lebih baik, dapat ditunjang dengan perhatian penting pada gizi anak sekolah dasar. Kegiatan dilakukan pada bulan Februari 2019 dan diikuti oleh 20 orang siswa kelas I SDN 03 Purworejo. Pelaksanaan kegiatan ini yang digunakan adalah pemeriksaan kesehatan siswa (berat badan dan tinggi badan) dan pemberian pendidikan kesehatan tentang gizi. Metode yang digunakan adalah metode ceramah, metode tanya jawab dan game/quiz. Hasilnya yaitu kesadaran siswa untuk mengikuti kegiatan pemeriksaan status gizi secara rutin dan mengonsumsi makanan dengan pola gizi seimbang. Beberapa faktor pendukung kegiatan tersebut antara lain : 1. Para peserta memiliki kemauan yang besar untuk mendapatkan informasi dan pengetahuan mengenai zatzat gizi yang bermanfaat bagi kesehatan tubuh, 2. Kegiatan pendidikan kesehatan ini sangat didukung oleh civitas akademika sekolah, yang secara spontan dan terstruktur ikut berpartisipasi secara aktif dalam pelaksanaan pendidikan kesehatan tentang gizi tersebut.. Kendala yang dihadapi dalam pelaksanaan kegiatan ini yaitu adanya keterbatasan dalam fasilitas pendukung untuk melakukan presentasi diantaranya tidak ada tayangan gambar/ slide dari LCD proyektor karena keterbatasan waktu dan kondisi. Dampak kegiatan ini bagi sekolah yaitu mengetahui status gizi siswa sehingga melahirkan program baru yaitu secara rutin mengukur status gizi siswa melalui pengukuran berat badan dan tinggi badan.
\end{abstract}

Kata kunci: Pendidikan; Kesehatan; Gizi; Usia Sekolah

\begin{abstract}
School children are who are at school age, namely between 6-12 years. At this age, a healthy child will experience normal and reasonable growth and development, that is, according to the physical growth standards of children in general and according to his age's ability standards. When entering elementary school age, children are in the early stages of learning, which will affect the child's learning process in the future. Therefore, it is important to pay attention to elementary school children's nutrition to support the physical condition of the brain, which is a requirement for children to have high intelligence to support children's learning achievement in a better direction. The activity was carried out in February 2019 and was attended by 20 grade I students of SDN 03 Purworejo. This activity's implementation is the student's health check (body weight and height) and health education about nutrition. The methods used are the lecture method, the question and answer method, and the game/quiz method. The result is students' awareness of routine nutritional status checks and eating foods with a balanced nutritional pattern. Some of the supporting factors for these activities include 1. The participants have a great willingness to get information and knowledge about nutritional substances beneficial to body health, 2. This health education activity is highly supported by the school, both directly and indirectly. Participate actively in the implementation of health education about nutrition. The constraints faced in the implementation of this activity are the limitations in supporting facilities for making presentations, including no image/slide display from the LCD projector due to limited time and conditions.
\end{abstract}


The impact on schools is knowing students' nutritional status so that it creates new programs, namely routinely measuring the nutritional status of students through measurements of body weight and height.

Keywords: Education; Health; Nutrition; School Age

\section{PENDAHULUAN}

Tingkat kesehatan, kecerdasan, dan produktivitas kerja yang tinggi menjadi salah satu ciri bangsa yang maju. Kesehatan individu serta masyarakat dapat ditingkatkan melalui keadaan gizi yang baik. Agar pertumbuhan serta perkembangan fisik dan kecerdasan bayi, anak-anak, serta seluruh kelompok umur dapat optimal, maka sangat penting dalam memperhatikan keoptimalan gizi. Agar berat badan normal atau sehat dan tubuh tidak mudah terkena penyakit infeksi, maka diperlukan gizi yang baik sehingga dapat meningkatkan produktivitas kerja dan melindungi dari penyakit kronis serta kematian dini. Gizi yang tidak optimal berkaitan dengan kesehatan yang buruk (Kemenkes RI, 2014).

Di masa depan, kualitas sumber daya manusia yang serius dapat disebabkan oleh kekurangan gizi di awal kehidupan karena dapat menjadikan pertumbuhan gagal, BBLR, tubuh yang kecil, kurus dan imunitas yang rendah. Serta dalam perjalanan waktu, kejadian kurang gizi ini dapat menghambat perkembangan kognitif dan pendidikan menjadi gagal sehingga menyebabkan tingkat produktivitas di masa dewasa rendah. Selain itu, angka terjadinya penyakit tidak menular contohnya diabetes, stroke, penyakit jantung, dan penyakit lainnya di masa usia dewasa diawali dari meningkatnya risiko gangguan metabolic yang disebabkan kurangnya gizi yang dialami saat awal kehidupan (Kemenkes RI, 2015).

Pembangunan yang berkesinambungan dihasilkan dari tangan generasi muda yang merupakan investasi suatu bangsa dimulai dari usia anak sekolah dengan gizi yang baik. Akibat yang dapat terjadi jika kekurangan gizi pada usia sekolah yaitu anak menjadi lemah, cepat lelah dan sakit-sakitan, sehingga anak menjadi sering tidak masuk serta mengalami kesukaran dalam mengikuti dan memahami pelajaran. Tahun 2013 dari Riskesdas menyajikan bahwa masih tingginya persentase anak usia 5-12 tahun yang kurus, pendek (stunting), gemuk dan anemia yaitu masing-masing 11,2\%, 30,7\%, 18,8\% dan 26,4\%. Persentasi ini digolongkan masih sangat tinggi (Sinaga, 2016), walaupun persentase anak sekolah dasar yang pendek di Indonesia menurun dari 35,8\% (Riskesdas 2010) menjadi 30,7\% (Riskesdas, 2013).

Menurut hasil pemantauan status gizi di Indonesia tahun 2016 presentase anak sekolah dan remaja umur 5-12 tahun yang tergolong sangat kurus dan kurus berdasarkan indeks 
IMT/U adalah2,7\% dan 7,8\%. Sedangkan di Jawa timur 2,2\% dan 7,8\% (Kemenkes RI, 2017). Hasil observasi status gizi di Indonesia tahun 2017, presentase anak sekolah dan remaja umur 5-12 tahun yang tergolong sangat kurus dan kurus berdasarkan indeks IMT/U adalah 3,4\% dan 7,5\%. Sedangkan di Jawa timur1,9\% dan 6,0\%. Menurut hasil pemantauan status gizi di Indonesia tahun 2017 persentase anak sekolah dan remaja umur 5-12 tahun yang tergolong sangat pendek dan pendek berdasarkan indeks TB/U adalah 8,3\% dan 19,4\%. Sedangkan di Jawa timur 3,5\% dan 17,1\% (Kemenkes RI, 2018).

Menurut Almatsier (2012), Status gizi dipengaruhi oleh konsumsi makanan dan penggunaan zat-zat gizi di dalam tubuh. Bila tubuh memperoleh cukup zat gizi dan digunakan secara efisien maka akan tercapai status gizi optimal yang memungkinkan pertumbuhan fisik, perkembangan otak, kemampuan kerja dan kesehatan secara umum pada tingkat setinggi mungkin.

Otak dalam perkembangannya dapat dipengaruhi oleh makanan, jika makanan tidak cukup mengandung zat-zat gizi yang diperlukan, dan keadaan ini terjadi terus-menerus, akan menjadikan perubahan metabolisme dalam otak berubah, berakibat terjadi ketidakmampuan berfungsi normal. Pada keadaan yang lebih berat dan kronis, kekurangan gizi menyebabkan pertumbuhan badan terganggu, badan lebih kecil diikuti dengan ukuran otak yang juga kecil. Jumlah sel dalam otak berkurang dan terjadi ketidakmatangan dan ketidaksempurnaan organisasi biokimia dalam otak. Keadaan ini berpengaruh terhadap perkembangan kecerdasan anak (Anwar, 2010).

Usia 6-12 tahun merupakan usia anak pada masa sekolah. Standar pertumbuhan fisik dan standar kemampuan yang normal dan wajar akan dimiliki oleh anak usia pada masa sekolah yang sehat sesuai kriteria sehat pada usianya. Proses belajar di masa depan pada anak usia sekolah dasar akan dipengaruhi oleh pertumbuhan dan perkembangannya di masa awal belajar ini. Maka daripada itu, penunjang kondisi otak agar berprestasi yang lebih baik, dapat ditunjang dengan perhatian penting pada gizi anak sekolah dasar (Adriani dan Wirjatmadi, 2012).

Dari survei awal yang dilakukan oleh tim pengabdian dengan pemberian kuesioner kepada siswa SDN 03 Purworejo, hasilnya 60\% siswa belum memiliki pengetahuan yang cukup mengenai gizi seimbang. Berdasarkan hasil wawancara awal dengan kepala sekolah, di SDN 03 Purworejo belum ada program untuk pengukuran status gizi siswa setiap bulan. Siswa SDN 03 Purworejo masih mengalami masa pertumbuhan dan perkembangan sehingga membutuhkan konsumsi pangan yang cukup dan bergizi seimbang. Oleh karena itu diperlukan usaha-usaha untuk dapat memberikan pemahaman kepada anak sekolah, agar 
mereka dapat memenuhi kebutuhan gizinya. Pendidikan gizi diperlukan untuk meningkatkan pengetahuan gizi siswa, membentuk sikap positif terhadap makanan bergizi dalam rangka membentuk kebiasaan makan yang baik (Fathehah, 2020). Hal ini sejalan dengan hasil penelitian yaitu ada pengaruh penyuluhan terhadap peningkatan pengetahuan tentang gizi seimbang dan PHBS pada siswa sekolah dasar negeri Cambayya Makassar (Sirajuddin, Masni dan Najamuddin, 2019).

Berangkat dari permasalahan tersebut maka STIKES Bhakti Husada Mulia Madiun tergerak untuk melaksanakan kegiatan berupa pemeriksaan status gizi (berat badan dan tinggi badan) dan pemberian pendidikan kesehatan tentang gizi seimbang yang merupakan salah satu langkah awal yang bisa dilakukan untuk perbaikan status gizi dan meningkatkan prestasi belajar anak sekolah.

Target dalam kegiatan pengabdian masyarakat ini adalah menjaga konsistensi pihak sekolah untuk rutin melakukan pemantauan status gizi peserta didiknya bekerjasama dengan puskesmas terdekat dan pemberian edukasi tentang gizi seimbang

\section{METODE}

Metode pengabdian ini menggunakan observasi secara langsung dan ceramah serta Tanya jawab mengenai gizi untuk anak usia sekolah di SDN Purworejo 03. Yang sebelumnya sudah didahului dengan persiapan obervasi responden yaitu mulai dari perijinan kepada STIKES Bhakti Husada Mulia, kemudian ke Kesbangpolinmas Kabupaten Madiun dan yang terakhir perijinan di tempat pelaksnaan kegiatan yaitu melalui Kepala Sekolah. Pelaksanaan kegiatan pengabdian masyarakat yang digunakan adalah pemeriksaan kesehatan anak usia sekolah (tinggi badan dan berat badan). Dalam program pendidikan kesehatan tentang gizi ini, digunakan beberapa metode antara lain: (i) Metode ceramah, yaitu digunakan untuk memaparkan materi yang telah disusun oleh tim. (ii) Metode tanya jawab, digunakan untuk merespon sejauh mana tingkat pemahaman peserta terhadap materi yang telah disampaikan. (iii) Game/ quiz, Kegiatan ini dilaksanakan selama dua hari yaitu tanggal 15-16 Februari 2019, yang dihadiri serta diantusiasi oleh siswa sejumlah 20 anak dan mitra yang terlibat yaitu SDN Purworejo 03. (iv) Metode observasi langsung dengan cara pemeriksaan tinggi badan dan berat badan.

\section{HASIL, PEMBAHASAN, DAN DAMPAK}

Kegiatan pengabdian masyarakat dilakukan pada bulan Februari 2019. Kegiatan diikuti oleh 20 orang siswa kelas 1 SDN 03 Purworejo. Pendidikan kesehatan tentang Gizi 
di Sekolah Dasar ini merupakan salah satu cara untuk meningkatkan derajat kesehatan pada anak sekolah, sehingga dapat dijadikan langkah awal untuk mengubah perilaku dari tidak sehat menjadi sehat.

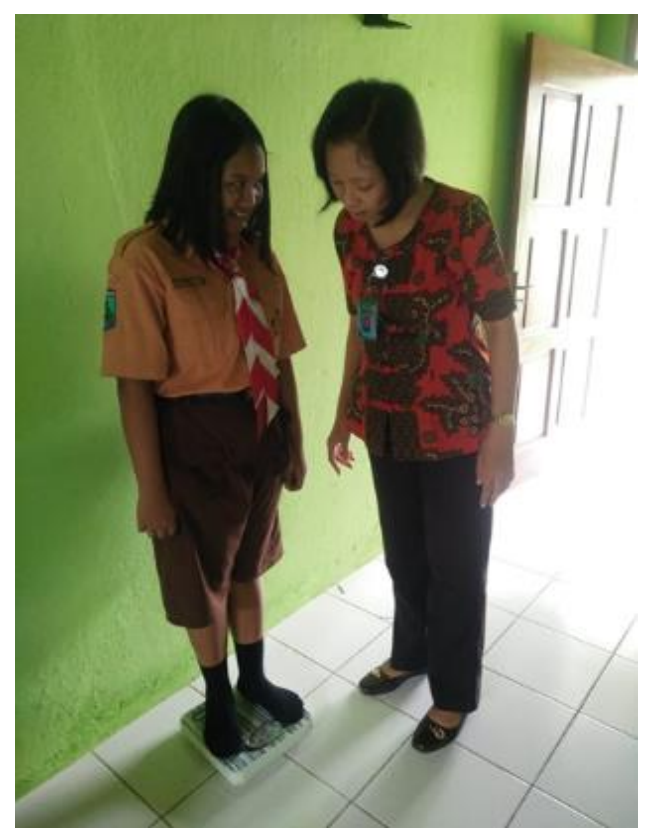

Gambar 1. Saat melakukan pengukuran Berat Badan

Dengan pendidikan kesehatan tentang gizi ini diharapkan anak sekolah sedikit demi sedikit mulai memahami manfaat gizi seimbang dan mengonsumsi makanan dengan pola gizi seimbang, mereka juga bisa memilah dan memilih makanan sehat yang bermanfaat bagi kesehatan tubuh.

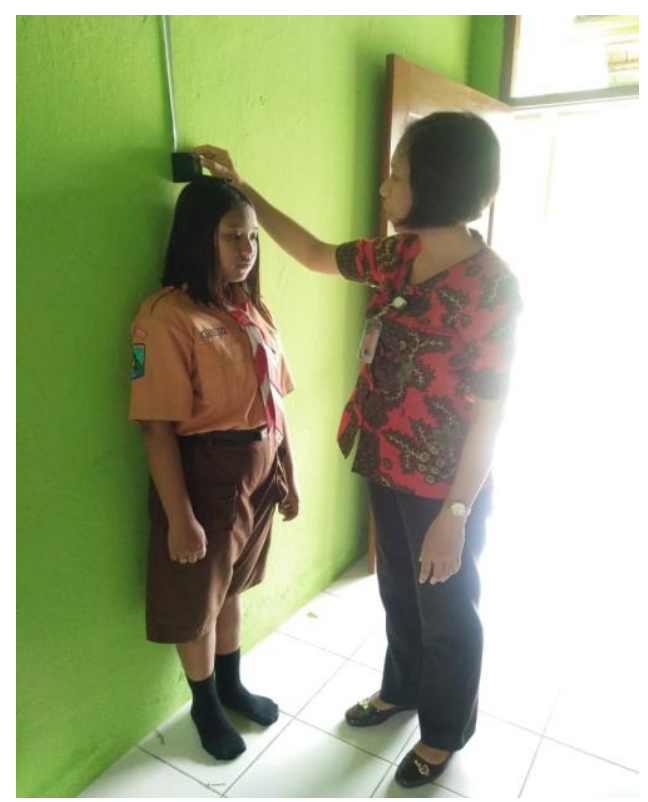

Gambar 2. Saat melakukan pengukuran Tinggi Badan 
Beberapa faktor pendukung kegiatan tersebut antara lain : 1. Para peserta memiliki kemauan yang besar untuk mendapatkan informasi dan pengetahuan mengenai zat-zat gizi yang bermanfaat bagi kesehatan tubuh. 2. Kegiatan pendidikan kesehatan ini sangat didukung oleh pihak sekolah, baik secara spontan maupun di belakang layar berpartisipasi secara aktif dalam pelaksanaan pendidikan kesehatan tentang gizi tersebut.

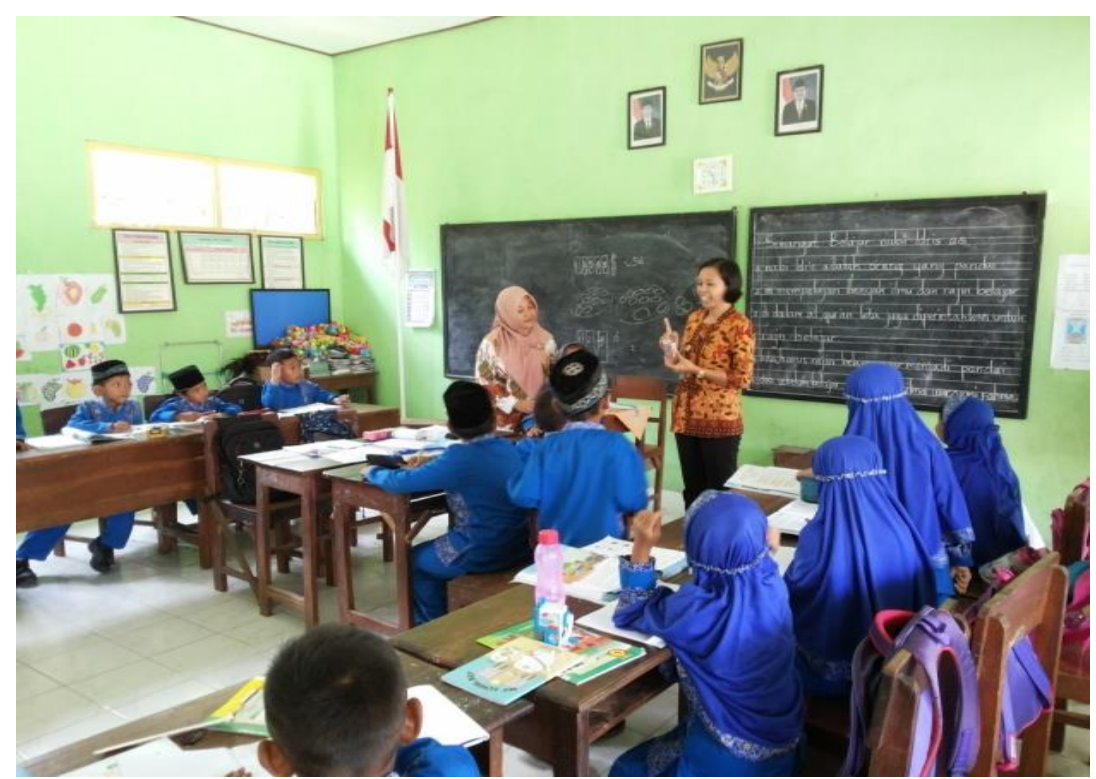

Gambar 3. Saat melakukan ceramah dan Tanya jawab

Peserta sangat antusias saat kegiatan games dimulai. Dengan adanya games, peserta merasa kegiatan ini tidak membosankan. Kuis ini menggunakan media handphone yang memutar lagu kemudian semua peserta harus mengikuti lagu tersebut sambil memutarkan satu bola. Kemudian ketika lagu dihentikan, bola akan berhenti pada satu peserta, dan peserta ini diminta untuk maju ke depan kelas, kemudian dilanjut sampai ada 2 anak yang sudah tertangkap. Kemudian diberikan beberapa kartu yang isinya pertanyaan mengenai materi yang diberikan. Kemudian kedua anak ini harus menjawab pertanyaan yang telah dipilih. 


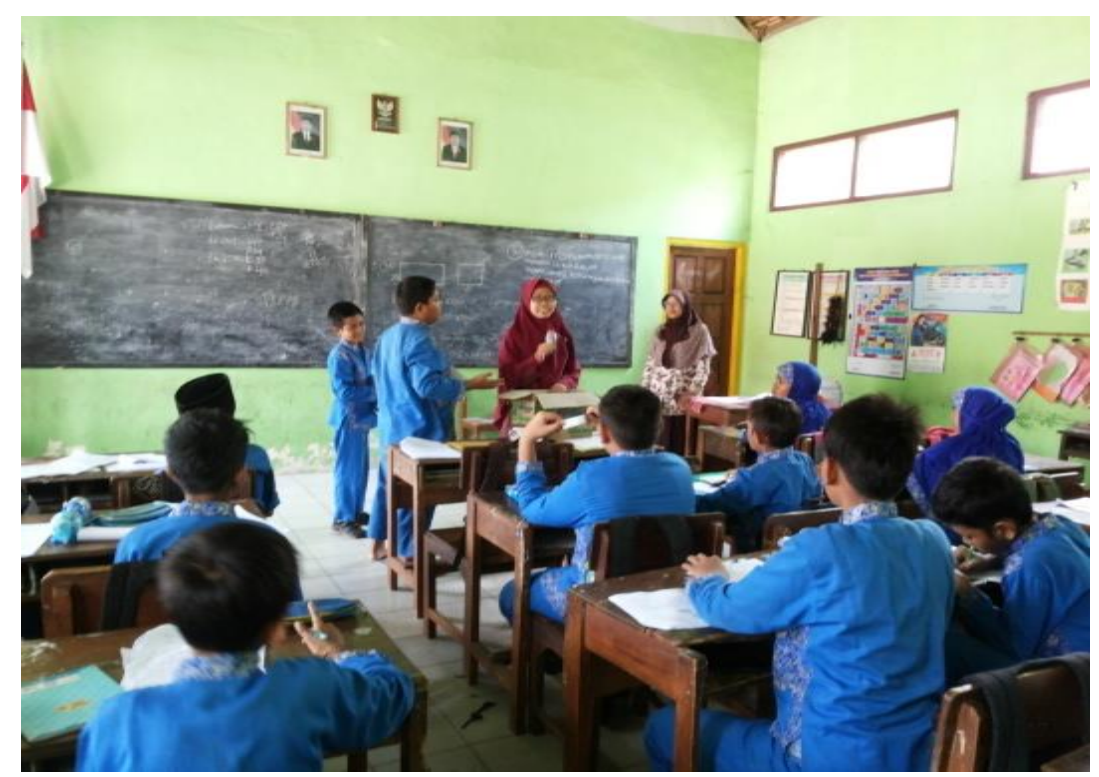

Gambar 4. Saat melakukan tanya jawab

Kendala yang dihadapi dalam pelaksanaan pendidikan kesehatan ini adalah adanya keterbatasan dalam fasilitas pendukung untuk melakukan presentasi diantaranya tidak ada tayangan gambar/ slide dari LCD proyektor karena keterbatasan waktu dan kondisi.

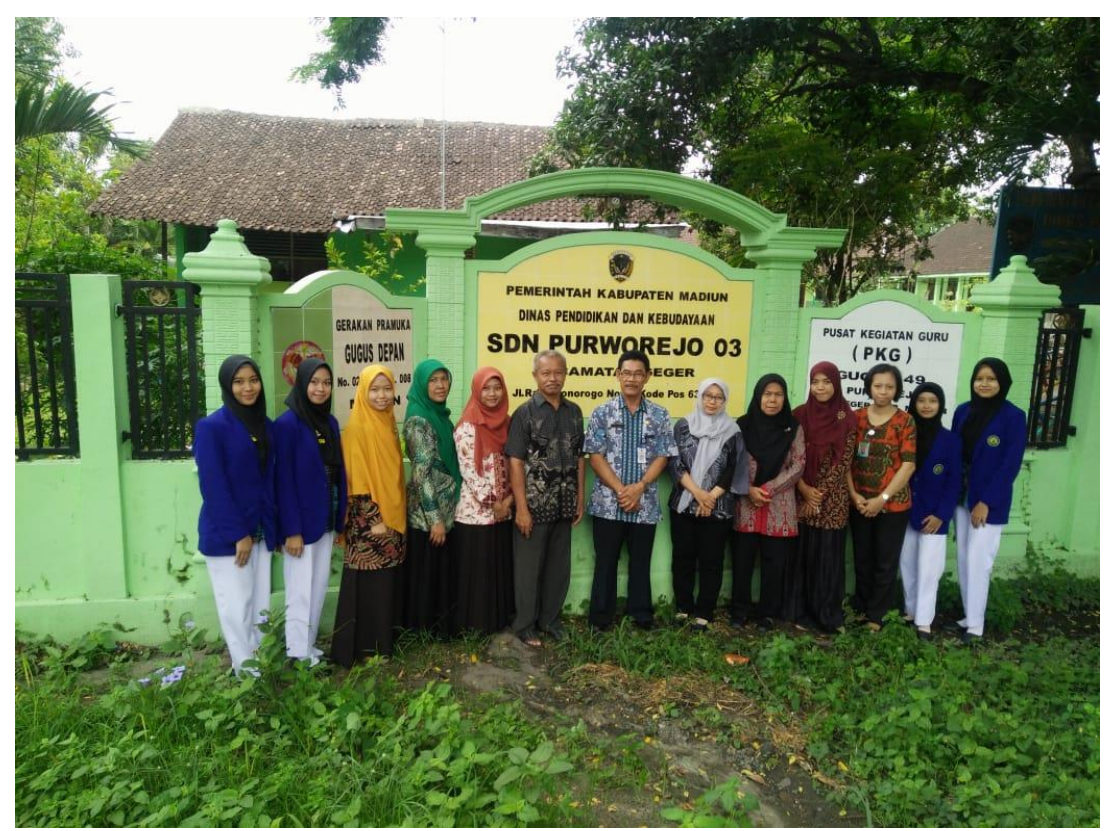

Gambar 4. Setelah selesai kegiatan pengabdian masyarakat

Sebelum dilakukan pendidikan kesehatan, terdapat $60 \%$ siswa yang belum memiliki pengetahuan yang cukup mengenai gizi seimbang dan berdasarkan hasil wawancara awal dengan kepala sekolah, di SDN 03 Purworejo, belum ada program untuk pengukuran status gizi siswa setiap bulan. Setelah dilakukan pendidikan kesehatan ini, 96\% siswa sudah memiliki pengetahuan yang cukup mengenai gizi seimbang dilihat dari hasil post tes yang dibagikan setelah ceramah. Selain itu, sekolah dapat mengetahui status gizi siswa sehingga 
akan melahirkan program baru yaitu secara rutin mengukur status gizi siswa melalui pengukuran berat badan dan tinggi badan

\section{SIMPULAN}

Kegiatan pendidikan kesehatan pendidikan kesehatan gizi usia sekolah sebagai upaya peningkatan prestasi belajar SDN Purworejo 03 Geger Madiun berjalan dengan lancar dan peserta antusias dalam mengikutinya. Peserta dan mitra dapat mengetahui tentang kondisi perkembangan status gizi dari anak didiknya. Kepala sekolah SDN Purworejo 03 setuju jika program ini akan dimasukkan dalam program sekolah setiap bulannya. Status gizi sangatlah penting untuk menunjang prestasi belajar di sekolah. Adanya keterbatasan dalam fasilitas pendukung untuk melakukan presentasi diantaranya tidak ada tayangan gambar/ slide dari LCD proyektor karena keterbatasan waktu dan kondisi.

\section{UCAPAN TERIMAKASIH}

Penulis mengucapkan terima kasih kepada STIKES Bhakti Husada Mulia yang telah mendukung terlaksananya kegiatan pengabdian masyarakat ini.dengan cara memberikan ijin. Penulis juga mengucapkan terima kasih kepada semua civitas akademika SDN Purworejo 03, yang telah mengijinkan dan memberi dukungan kegiatan pengabdian ini.

\section{DAFTAR PUSTAKA}

Adriani, M. dan B., Wirjatmadi. 2012. Peranan Gizi dalam Siklus Kehidupan. Jakarta: Prenadamedia Group

Almatsier, S. 2012. Prinsip Dasar Ilmu Gizi. Gramedia Pustaka Utama. Jakarta

Anwar. 2010. Hidup Sehat Gizi Seimbang Dalam Siklus Kehidupan Manusia. Jakarta: PT Primamedia Pustaka

Badan POM RI. 2013. Pedoman Pangan Jajanan Anak Sekolah untuk Pencapaian Gizi Seimbang bagi Pengawas dan/atau Penyuluh. Jakarta: Direktorat Standardisasi Produk Pangan, Deputi Bidang Pengawasan Keamanan Pangan dan Bahan Berbahaya, Badan Pengawas Obat dan Makanan RI

Fathehah, Rahma. 2020. Perbedaan Pengetahuan Sebelum Dan Sesudah Pemberian Pendidikan Kesehatan Tentang Gizi Seimbang Melalui Media Video Animasi Di SD Mardi Rahayu Kabupaten Semarang. S1 thesis, Universitas Ngudi Walyo

Kemenkes RI. 2014. Pedoman Gizi Seimbang. Jakarta: Kemenkes RI

Kemenkes RI. 2015. Status Gizi Pengaruhi Kualitas Bangsa. www.depkes.go.id (diakses 11 Januari 2019) 
Kemenkes RI. 2018. Buku Saku Pemantauan Status Gizi Tahun 2017. Jakarta: Kemenkes RI

Kemenkes RI. 2017. Hasil Pemantauan Status Gizi dan Penjelasannya Tahun 2016. Jakarta: Kemenkes RI

Sinaga, T. 2016. Gizi Anak Sekolah. http://repository.ipb.ac.id (diakses 11 Januari 2019)

Sirajuddin, S., Masni, M., \& Najamuddin, U. 2019. Peningkatan praktek gizi seimbang dan PHBS Pada murid sekolah dasar. Media Gizi Pangan, 25(2), 13-19. 